\title{
Comparative Study Between Tubularized Incised Urethral Plate and Tubularized Incised Plate with Preputial Graft in Hypospadias Repair Sultan Mohamed Sultan ${ }^{1}$, Tarek Mohamed AbdelBaky ${ }^{1}$, Mohamed ElShazly, Khaled Mohamed Magdy Zein Elabden Youssef" ${ }^{*}$, Atef Badawy ${ }^{1}$ \\ ${ }^{1}$ Department of Urology, Faculty of Medicine, Menoufia University, Menoufia, Egypt \\ ${ }^{2}$ Department of Urology, Faculty of Medicine, Kafr El-Sheikh University, Kafr El-Sheikh, Egypt *Corresponding author: Khaled M.Zein Elabden, Mobile: (+20)1025320013, E-mail: ddrkhaled@ yahoo.com
}

\begin{abstract}
Background: Hypospadias is a common congenital anomaly, affecting approximately 1 of 300 live male births making hypospadias the second most common birth defect in boys after cryptorchidism. there are more than 100 techniques for urethral reconstruction among these techniques the tubularized incised urethral plate (TIP) which was proposed by Snodgrass in 1994 has been the most popular technique for the repair of primary hypospadias.

Objective: To study the difference between tubularized incised urethral plate and tubularized incised plate with preputial graft in hypospadias repair.

Patient and methods: This prospective randomized study included sixty patients suffering from hypospadias who was admitted to the urology department of Menoufia and Kafr El-Sheikh University Hospitals from December 2018 to June 2020 which were randomized into two groups; group I underwent the classic TIP repair and group II underwent TIP repair with inlay preputial graft. Operative details, postoperative complications were reported also uroflowmetry was done for all cases at the 3rd and 6th months postoperatively.

Results: There was no significant difference between both techniques regarding the postoperative complications and overall success rate (P 0.718) which were $83.3 \%$ and $86.7 \%$ in A and B respectively. The uroflowmetry at $3^{\text {rd }}$ month postoperatively showed no significant groups difference in $\mathrm{Q}$ max between both groups $(\mathrm{p}>0.05)$ while there was a significant improvement in Q max in the $6^{\text {th }}$ month in the grafted group (p. 0.001)

Conclusion: despite both the classic TIP repair and TIP with preputial graft were comparable according to the overall success rate and postoperative complications the grafted TIP was more superior to classic TIP in the functional outcomes which were assessed by the uroflowmetry ( $\mathrm{Q}$ max).
\end{abstract}

Keywords: Tubularized incised urethral plate, Tubularized incised plate, Hypospadias.

\section{INTRODUCTION}

Hypospadias is a congenital anomaly of the anterior urethra of males where the urethral opening presents more proximal than its normal glanular position. It is a common congenital anomaly, affecting approximately 1 of 250 live male births making hypospadias the second most common birth defect in boys after cryptorchidism ${ }^{(1)}$. Hypospadias may be associated with abnormal ventral curvature of the penile shaft which is called chordee ${ }^{(2,3)}$.

The tubularized incised plate (TIP) repair is based on an old principle of urethral plate tubularization which is known as the Thiersch-Duplay procedure ${ }^{(4)}$. if the urethral groove was not wide enough for tubularization in situ, alternative approaches such as the Mathieu urethroplasty or a vascularized island flap were determined (5). In 1994, Snodgrass popularized the concept of urethral plate incision with subsequent tubularization and secondary dorsal healing for primary hypospadias repair. Not surprisingly, the principle of incising the urethral plate had been employed before, but for different purposes ${ }^{(6)}$. In 1987 Ordeszewski incised the plate to achieve easier tubularization in redo cases where the urethral plate is often scarred ${ }^{(7)}$. In 1998 Spagnoli had reported the use of a dorsal inlay graft for urethroplasty for primary hypospadias to initiate healing of the IP by epithelialization and to augment the narrow urethral plate $^{(8)}$.

Later on; Kolon and Gonzales ${ }^{(9)}$ reported inner preputial graft allows the surface area of the healthy epithelium in neourethra rather than the raw area of traditional TIP ${ }^{(9)}$.

This work aimed to study the difference between tubularized incised urethral plate and TIP with preputial graft in hypospadias repair.

\section{PATIENTS AND METHODS}

A prospective randomized study included patients suffering from hypospadias who were admitted to the Urology Department of Menoufia and Kafr El-Sheikh University Hospitals during the period of study from December 2018 to June 2020.

The study design: It is a prospective randomized study which was conducted on Sixty patients who were included and divided randomly into Group I: (30 patients), underwent TIP repair and Group II: (30 patients), who underwent TIP repair with inlay preputial graft. (Grafted TIP)

The patients were randomized as follows; every odd number of the patients was given in group (A) for TIP repair, and every even number was given in group (B)

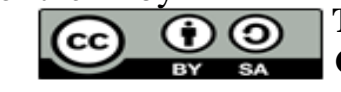


for Tubularized incised urethral plate (TIP) repair with inlay preputial graft.

Ethical consideration: Approval of the study protocol by the Ethical Scientific Committee of Menoufia University was obtained and informed consent was taken from all child parents before their enrollment in the study.

Inclusion criteria: Male Children till 16 years old with primary hypospadias and not recurrent cases.

Exclusion criteria: failed repair, sacrificed urethral plate, and chordee more than 60 degrees.

Patient Evaluation: All patients were preoperatively evaluated by Complete history taking.

Physical examination included: General examination: For detection of any other associated anomalies, Examination of the external genitalia included: (The meatus was examined for its position, caliber, and the condition of the nearby skin). (The urethral plate was examined for its shape, width, depth, and length in $\mathrm{mm}$ ). (The glans was examined for its shape, size, presence of the urethral pit and glanular groove whether it is deep, shallow, or flat), (The prepuce was examined, partial absence of the prepuce, which usually covers the entire glans), (The presence of penile torsion), (The scrotum was examined for its shape, well developed or not, its contents (palpation of the testis) if it was present or absent (undescended), its site, size, bilateral symmetry or any associated problem as a congenital hydrocele or inguinal hernia).

Routine investigations: Laboratory: Complete urine analysis and urine culture if necessary, Complete blood picture, Bleeding and coagulation times, Prothrombin time and activity and Radiological: Abdomino-pelvic ultrasonography if there was associated undescended testis.

The surgical procedures: Preoperative Preparation: Preoperative antibiotic was administered as a single dose of broad-spectrum parenteral antibiotic for all patients at operation room before the procedure in the form of a third-generation cephalosporin, Anesthesia: General with caudal analgesia or penile block, Positioning: Supine position, Skin preparation: In operative theatre, the smegma was removed and Povidone-iodine shampoo and saline wash was done. Then, the skin was painted with povidone-iodine, Magnification: Optical loupes were used $(2.5 \mathrm{X})$.

Steps: 1- Firstly; the glans is fixed by traction suture using a 5-0 silk just distal to the anticipated neomeatus. 2- Initial subcoronal skin incision was done. Then degloving of the penile skin down to the penoscrotal junction, artificial erection was done cases with curvature more than 60 degrees were excluded from the study.

3-Two longitudinal incisions were made along the visible junction of the glans wings to the urethral plate (UP).

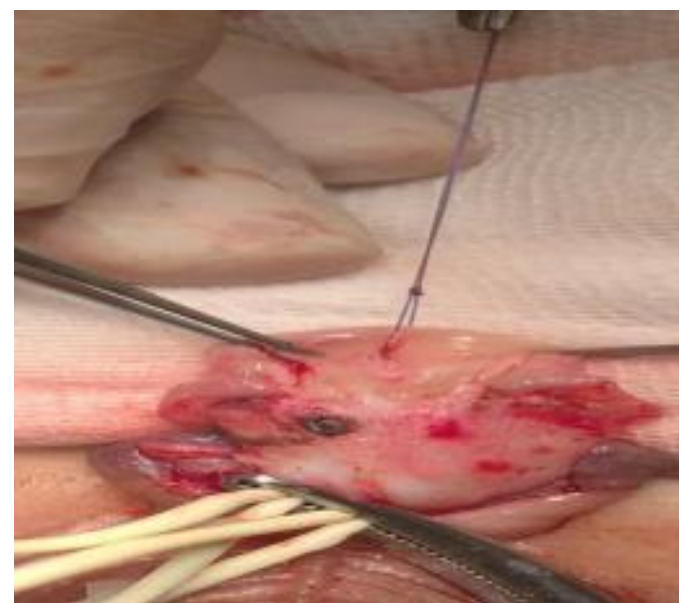

4- The glans wing was dissected and freely mobilized using dissecting scissors.

5- An incision was made in the midline by using a scalpel then deepened by scissor starting from the hypospadias native meatus and extending distally beyond the margins of the UP into glans to the urethral or glanular nub which is usually 3-4 mm proximal to the tip of the penis thus relaxing the UP those who underwent TIP with preputial graft technique the incision was slightly extended.

6- In preputial graft group (Group B): small rectangular or diamond-shaped free graft was harvested from the inner prepuce and was fenestrated and fixed in the IUP using 7-0 polydioxanone (PDS). 


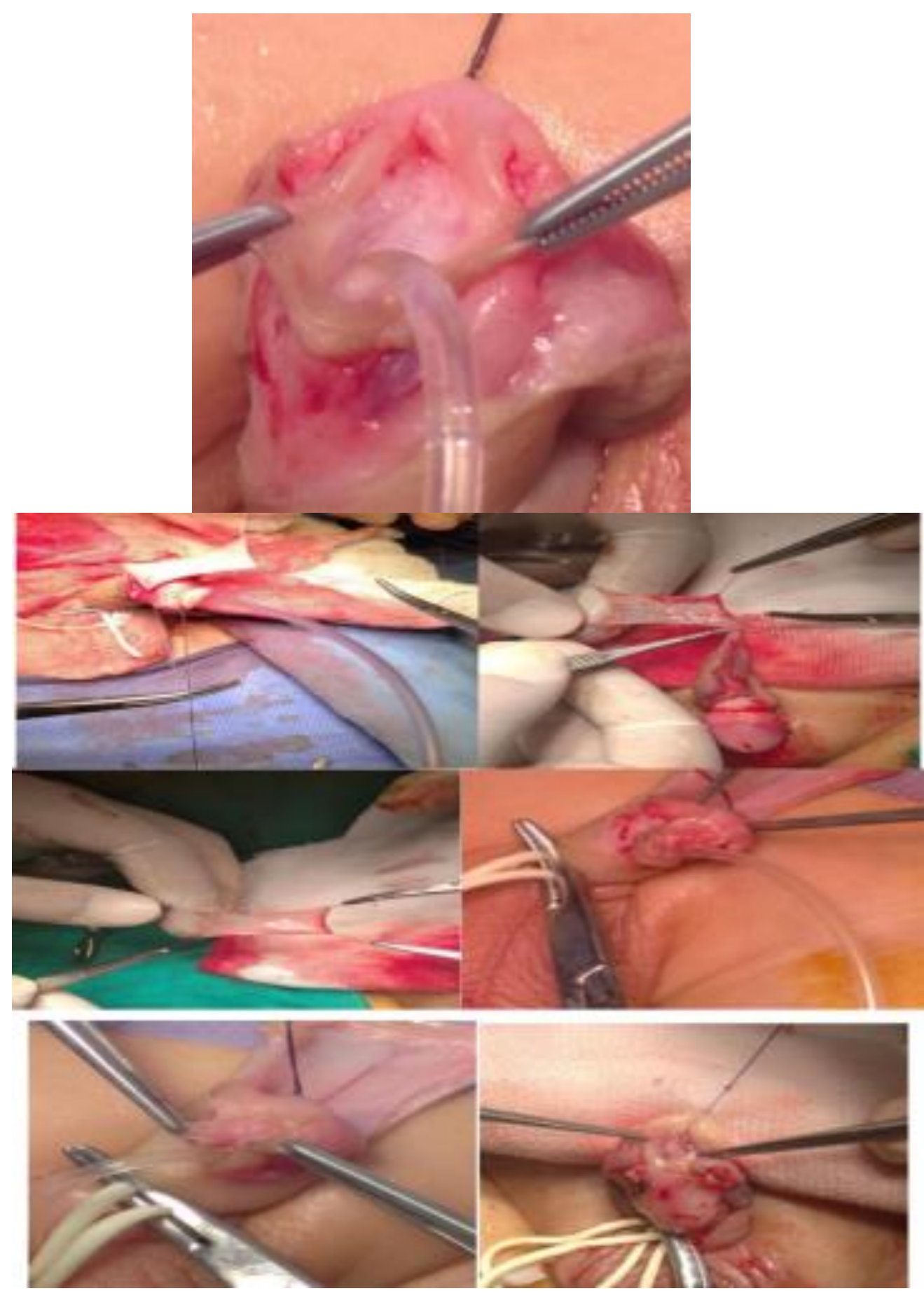

7- Then neourethra was tubularized over a $6 \mathrm{~F}$ catheter using 7-0 polydioxanone (PDS) continuous subcuticular sutures then this suture line is doubled with another interrupted subcuticular sutures. 
https://ejhm.journals.ekb.eg/
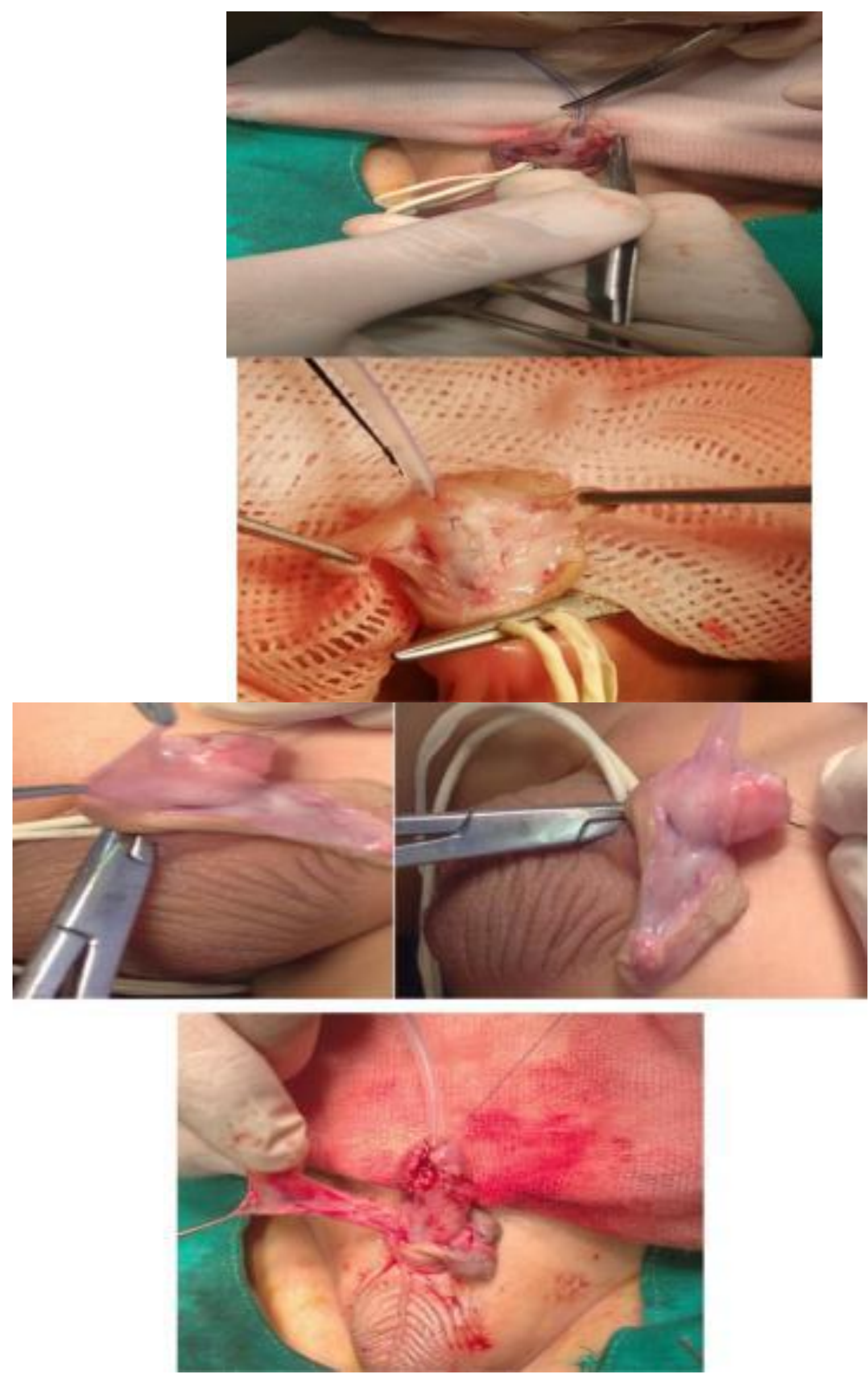

8- Single or double-layered well-vascularized dartos flap by the prepuce and dorsal penile-shaft was transposed ventrally and fixed to cover the suture line of the neourethra. 
9- The glans wings were approximated for glansplasty using interrupted subepithelial polydioxanone (PDS)Sutures.
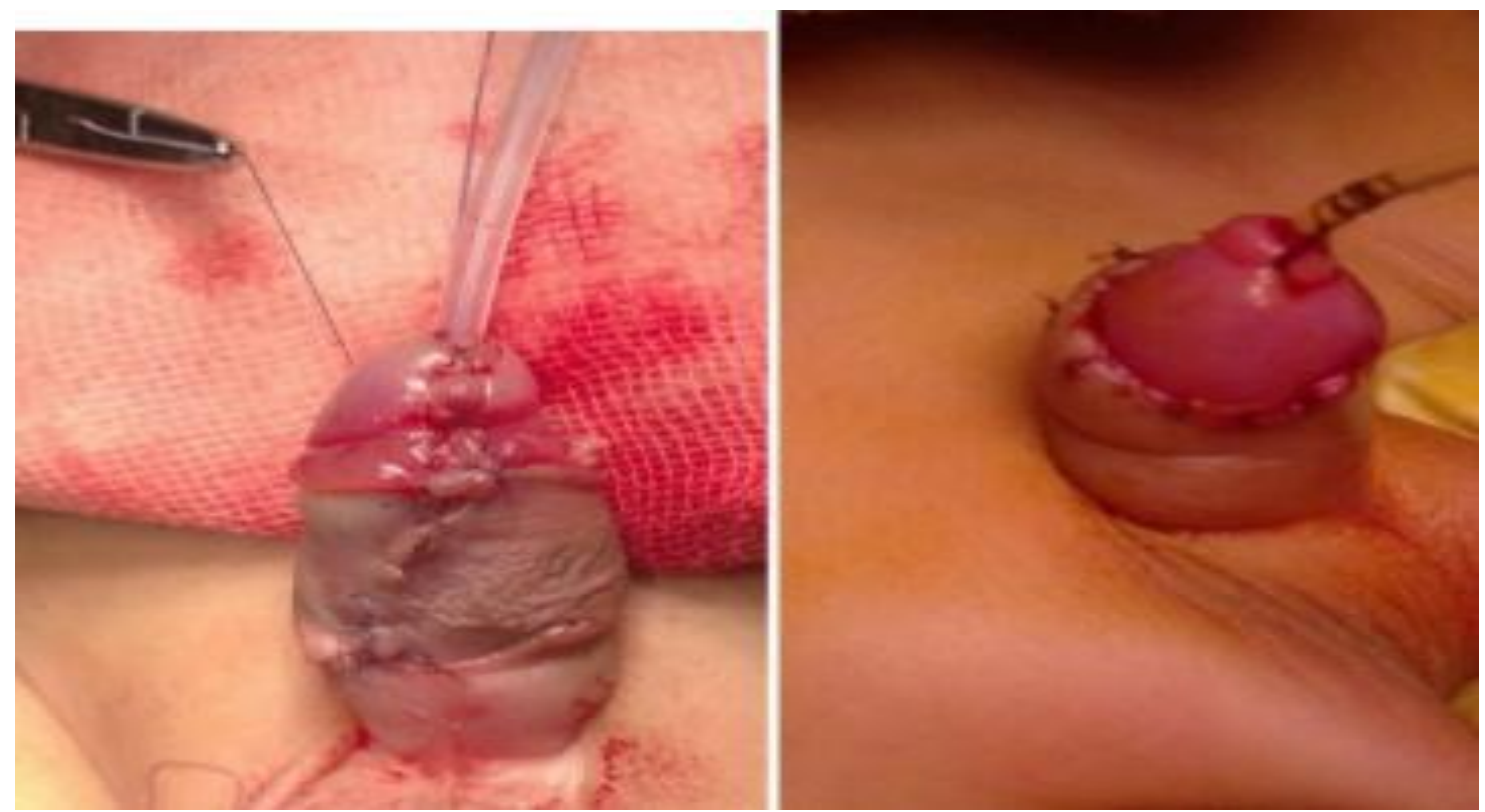

10- The mucosal subcoronal collar is approximated and closed then ventral shaft skin was then closed in the midline by interrupted subepithelial 6-0 vicryl sutures.
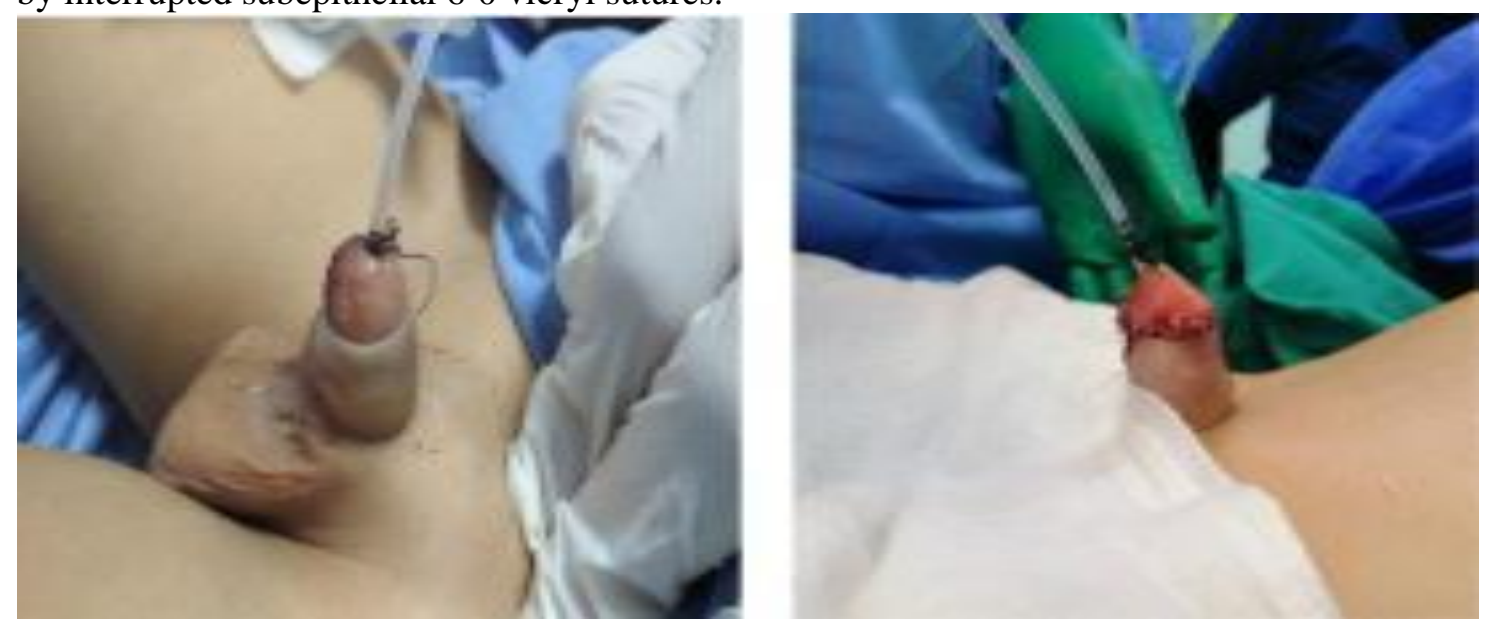

11- The dressing was done and left in the place for three days.

12- The catheter was left lodging in a diaper for 7days was applied and the stent was left open dripping into a diaper (double diaper technique).

Postoperative care: All patients were discharged from the $2^{\text {nd }}$ to $5^{\text {th }}$-day postoperative day and received an oral broadspectrum antibiotic for ten days. They were also received anticholinergic and analgesics to decrease the postoperative bladder spasm. The dressing was removed on $3^{\text {rd }}$ day of operation and the wound was cared by Seitz bath and antibiotic ointment four times per day.

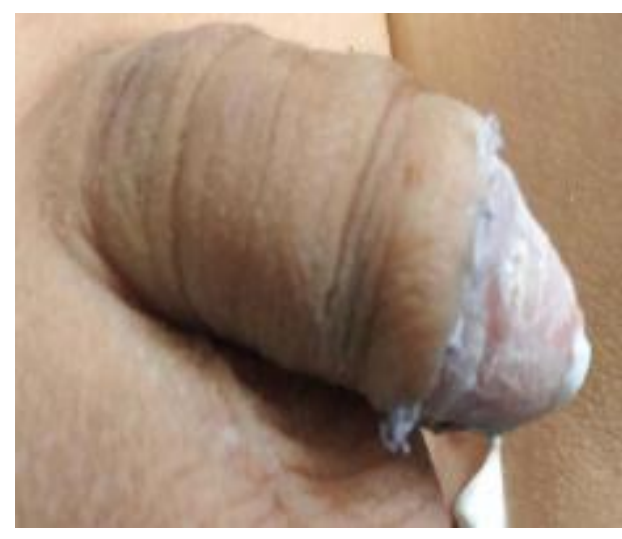


Follow-up: Schedule: first visit one week for catheter removal then after 4 weeks, 6 weeks, 3 months, 6 months. By local examination of the penis for the neomeatus for its position, the calibration of the neourethra by insertion of a feeding tube or Nelaton catheter sized $8 \mathrm{Fr}$ for about $1 \mathrm{~cm}$ to detect if there is neourethral stricture or not and the penile shaft for shape and its straightness, Evaluation of the functional voiding symptoms and Uroflowmetry was done at the 3 months and 6 months visit for toilet trained children.

The success of the procedure was determined by achieving normal minimal skin scarring and functional normal urine stream and normal uroflowmetry.

\section{Statistical Analysis}

Results were tabulated and statistically analyzed using standard computer program using MICROSOFT EXCEL 2019 and SPSS V.25 program for MICROSOFT WINDOWS 10. Chi-Squared $\left(\chi^{2}\right)$, t-test, and MannWhitney (U) test were used.

\section{RESULTS}

Regarding the demographic data of there was no significant difference between both groups regarding age which ranged from 9 months to 12 years old and age in months ranged from 9 months to 144 months with the median age in group $\mathrm{A}$ of 30.0 months and group B 36.0 months in group B. According to the urethral pate criteria, there was no significant difference between both groups.

The mean length of the urethral plate in group A was $12.06 \pm 5.14 \mathrm{~mm}(6.0-21.0 \mathrm{~mm})$ while in group B the mean urethral plate length was $10.01 \pm 4.57 \mathrm{~mm}$ (5.9-20.0 mm). As well, the mean glans width in group A was $14.57 \pm 2.06 \mathrm{~mm}(10.9-18.0 \mathrm{~mm})$ and in group B $14.71 \pm 1.90 \mathrm{~mm}(11.0-18.0 \mathrm{~mm})$. Regarding operative time, there was a significant difference between both techniques. The operative time was longer in group B compared to group A (P 0.00), as shown in table 1.

Table (1): Comparison between the two studied groups according to age, preoperative urethral plate criteria, and glanular width, and operative time between two techniques.

\begin{tabular}{|c|c|c|c|c|}
\hline & $\begin{array}{c}\text { Group A } \\
(\mathbf{n}=\mathbf{3 0})\end{array}$ & $\begin{array}{c}\text { Group B } \\
(\mathbf{n}=\mathbf{3 0})\end{array}$ & $\mathbf{T}$ & P-value \\
\hline $\begin{array}{l}\text { Age (months) } \\
\text { Min. - Max. } \\
\text { Median }\end{array}$ & $\begin{array}{c}9.0-144.0 \\
30.0\end{array}$ & $\begin{array}{c}12.0-96.0 \\
36.0\end{array}$ & $\begin{array}{c}\mathrm{U}= \\
349.0\end{array}$ & 0.13 \\
\hline $\begin{array}{l}\text { Width of the urethral plate }(\mathbf{m m}) \\
\text { Min. - Max. } \\
\text { Mean } \pm \text { SD. } \\
\text { Median }\end{array}$ & $\begin{array}{c}4.0-9.0 \\
5.63 \pm 1.25 \\
5.20\end{array}$ & $\begin{array}{c}4.0-7.0 \\
5.92 \pm 1.35 \\
5.70\end{array}$ & 0.871 & 0.388 \\
\hline $\begin{array}{l}\text { Width of the urethral plate after incision } \\
(\mathbf{m m}) \\
\text { Min. - Max. } \\
\text { Mean } \pm \text { SD } \\
\text { Median }\end{array}$ & $\begin{array}{c}4.2-10.0 \\
7.67 \pm 1.40 \\
7.5\end{array}$ & $\begin{array}{c}5.90-20.0 \\
7.96 \pm 1.41 \\
7.5\end{array}$ & 0.569 & 0.572 \\
\hline $\begin{array}{l}\text { Length of the urethral plate }(\mathbf{m m}) \\
\text { Min. - Max. } \\
\text { Mean } \pm \text { SD. } \\
\text { Median }\end{array}$ & $\begin{array}{c}6.0-21.0 \\
12.06 \pm 5.14 \\
11.5\end{array}$ & $\begin{array}{c}5.9-20.0 \\
10.01 \pm 4.57 \\
7.5 .0\end{array}$ & 1.637 & 0.107 \\
\hline $\begin{array}{l}\text { Glans width }(\mathbf{m m}) \\
\text { Min. }- \text { Max. } \\
\text { Mean } \pm \text { SD. } \\
\text { Median }\end{array}$ & $\begin{array}{c}10.9-18.0 \\
14.57 \pm 2.06 \\
14.0\end{array}$ & $\begin{array}{c}11.0-18.0 \\
14.71 \pm 1.90 \\
15.0\end{array}$ & 0.266 & 0.791 \\
\hline $\begin{array}{l}\text { Operation time } \\
\text { Min. }- \text { Max. } \\
\text { Mean } \pm \text { SD. } \\
\text { Median }\end{array}$ & $\begin{array}{c}62.0-80.0 \\
74 \pm 8.00 \\
72.50\end{array}$ & $\begin{array}{c}78.0-112.0 \\
102.37 \pm 9.27 \\
90.50\end{array}$ & 8.207 & $0.00^{*}$ \\
\hline
\end{tabular}

The comparison between both groups in uroflowmetry in the $3^{\text {rd }}$ month the mean in group A was $15.26 \pm 4.02 \mathrm{ml} / \mathrm{sec}$ and in group $\mathrm{B}$ the mean was $17.00 \pm 2.58 \mathrm{ml} / \mathrm{sec}$ with no significant value $(\mathrm{P}>0.05)$ but the comparison between both groups in the $6^{\text {th }}$ month there was a significant difference as group B $(18.59 \pm 3.33 \mathrm{ml} / \mathrm{sec})$ showed a higher reading in the $\mathrm{Q}$ max value compared by group A $(10.89 \pm 2.15)$. by comparing between $3^{\text {rd }}$ month and $6^{\text {th }}$-month uroflow in the same group there was no significant difference in $\mathrm{Q}$ max at group A while at group B there was a significant improvement in $\mathrm{Q}$ max in the $6^{\text {th }}$ month $(\mathrm{P}=0.000)$, as shown in table 2 . 
Table (2): Comparing the uroflow at the $3^{\text {rd }}$ and $6^{\text {th }}$ month postoperatively in each group.

\begin{tabular}{|c|c|c|c|c|}
\hline & $\begin{array}{c}\text { Group A } \\
(n=19)\end{array}$ & $\begin{array}{c}\text { Group B } \\
(n=22)\end{array}$ & $\mathbf{T}$ & P-value \\
\hline $\begin{array}{l}\text { Uroflow after 3months } \\
\text { Min. - Max. } \\
\text { Mean } \pm \text { SD. } \\
\text { Median }\end{array}$ & $\begin{array}{c}7.0-20.0 \\
15.26 \pm 4.02 \\
16.0\end{array}$ & $\begin{array}{c}11.0-21.0 \\
17.00 \pm 2.58 \\
17.50\end{array}$ & 1.483 & 0.146 \\
\hline $\begin{array}{l}\text { Uroflow after } 6 \text { months } \\
\text { Min. - Max. } \\
\text { Mean } \pm \text { SD. } \\
\text { Median }\end{array}$ & $\begin{array}{c}7.0-17.0 \\
10.89 \pm 2.15 \\
11.0\end{array}$ & $\begin{array}{c}8.0-22.0 \\
18.59 \pm 3.33 \\
20.0 \\
\end{array}$ & 7.462 & $0.000 * *$ \\
\hline $\mathbf{T}$ & 1.667 & 8.618 & & \\
\hline P-value & 0.104 & $0.00 *$ & & \\
\hline
\end{tabular}

The main postoperative complications that occurred were meatal stenosis, Glanular dehiscence, and urethra cutaneous fistula. These complications were not statistically significant; meatal stenosis was detected in three cases in group A (10\%) and one case in group B (3.3\%). All cases were detected by the $4^{\text {th }}$ and $6^{\text {th }}$ week follow up and improved after regular dilatation. Three cases with urethrocutaneous fistula were documented in group A (10\%) and two cases in group B (6.7\%) all cases with fistulae were diagnosed after catheter removal. Also, Glanular dehiscence occurred in one case in each group which represents $3.33 \%$ of all cases. The overall success was $83.3 \%$ and $86.7 \%$ in $\mathrm{A}$ and $\mathrm{B}$ respectively, which were comparable between both groups ( $\mathrm{P} 0.718)$, as shown in table 3 . groups

Table (3): Postoperative complications and overall success rate in both techniques

\begin{tabular}{|l|c|c|c|c|c|c|}
\hline \multirow{2}{*}{} & \multicolumn{2}{|c|}{$\begin{array}{c}\text { Group A } \\
(\mathbf{n = 3 0})\end{array}$} & \multicolumn{2}{c|}{$\begin{array}{c}\text { Group B } \\
(\mathbf{n}=\mathbf{3 0})\end{array}$} & \multirow{2}{*}{$\chi^{\mathbf{2}}$} & \multirow{2}{*}{ P-value } \\
\cline { 2 - 6 } & No. & $\mathbf{\%}$ & No. & \% & & \\
\hline Presence of fistula & 3 & 10.0 & 2 & 6.7 & 0.218 & 0.640 \\
\hline Meatal stenosis & 3 & 10.0 & 1 & 3.3 & 1.071 & 0.301 \\
\hline $\begin{array}{l}\text { Glanular } \\
\text { Dehiscence }\end{array}$ & 1 & 3.3 & 1 & 3.3 & 0.0 & 1.000 \\
\hline Overall success & 25 & 83.3 & 26 & 86.7 & 0.131 & 0.718 \\
\hline
\end{tabular}

\section{DISCUSSION}

Hypospadias is one of the commonest genitourinary anomalies with an incidence of 1 every 250 to 300 of life male births, there are more than 100 techniques for urethral reconstruction among this technique the tubularized incised urethral plate (TIP) which proposed by warren Snodgrass in 1994 has been the most popular technique for the repair of primary hypospadias. TIP repair is a very simple procedure, short learning curve with few complications, and results in the creation of a normal-appearing meatus ${ }^{\left({ }^{6}\right.}$.

The most common complications after TIP urethroplasty are urethrocutaneous fistula, meatal stenosis, urethral stricture, and glanular dehiscence. The results for more than 2000 patients who had undergone TIP urethroplasty for primary hypospadias urethroplasty have been published and the mean overall complication rate was $10.8 \%$ (range, $0-33.3 \%$ ); the mean of urethrocutaneous fistula was 5.7\% (range, $0-21.2 \%$ ) while the mean of meatal stenosis was $4.7 \%$ (range, 0-19.0\%) and mean rate of glanular dehiscence was $1.3 \%$ (range, $0-4.2 \%$ ), ${ }^{(13)}$. Many published studies reported that the shallow incised urethral plate, small glans size, and if the incision extending distal to the glanular nob the incised plate often heals by fibrosis and increases the complications rate. ${ }^{(13,14)}$ However, if the incision does not reach distal enough the cosmetic outcome will be suboptimal, contributing to a not slit-like meatus ${ }^{(\mathbf{1 4})}$. TIP repair has been based on the theory that a deep midline incision of plate facilitates its widening and allows a tension-free tubularization but unfortunately, the incised bed of the urethral plate heals by more granulation and subsequent fibrosis, which has been proposed to be an attributing factor for the development of urethral strictures in many cases reported occasionally in the literature. Similarly, the development of meatal stenosis has been attributed to the distal extension of the incision into the glans, which often prevents the reconstruction of a neomeatus at the tip of the glans ${ }^{(15)}$.

Later on; Mouravas et al. (16) reported a comparative analysis of classic TIP and grafted TIP in 47 cases and reported that grafted TIP results in the lower fistula and urethral stricture rates, thus 
recommending it as the procedure of choice in patients undergoing primary hypospadias repair ${ }^{(\mathbf{1 7})}$.

In a retrospective study

of a single surgeon's experience with TIP and grafted TIP, the results of grafted TIP were superior to ordinary TIP urethroplasty as the grafted TIP was found to have significantly lower rates of fistula and meatal stenosis (14). In another series of 102 hypospadias cases that underwent grafted TIP the results were very promising as no case had developed meatal stenosis but fistula occurred in only 10 cases $(9.8 \%),{ }^{(18)}$.

However, Holland and Smith ${ }^{(19)}$ had reported that the complications rate increase when urethral plate width is $<8 \mathrm{~mm}$ (fistula rate $55 \%$ and meatal stenosis 18\%) Nguyen and Snodgrass ${ }^{(20)}$ reported that thirty cases with urethral plate width less than $8 \mathrm{~mm}$ underwent classic TIP and only in one patient developed a fistula and no reported cases with meatal stenosis and concluded that the width of the urethral plate did not affect the outcomes for a short term (8 months). One of the drawbacks of this study was that the narrow urethral plate was not studied as a univariant affecting the success of TIP urethroplasty (20).

The overall success in our study was comparable between TIP $(83.3 \%)$ and TIP with a preputial graft $(86.7 \%)$ also the incidence of complications between both groups was comparable the TIP group the urethrocutaneous fistula occurred in three cases from 30 cases $(10 \%)$ and ingrafted TIP group fistula occurred in two cases from 30 cases $(6.7 \%)$, meatal stenosis occurred in 4 cases (13.3) 3 (10\%) in TIP group and $1(3 \%)$ in grafted TIP group while two cases were presented with glanular dehiscence one in each group $(3.3 \%)$ however; the operative time was significantly longer in the grafted TIP group.

By comparing these results with the literature, it is comparable as meta-analysis published in 2015 for complication rates of the (TIP) repair included 49 studies (4675 patients) Fistula rate (5.7\%) in distal hypospadias $(10.3 \%)$ in proximal hypospadias, meatal stenosis $(3.6 \%)$ in distal hypospadias and $(4.4 \%)$ in proximal type ${ }^{\mathbf{( 2 2})}$.

Our results were also comparable to a recent meta-analysis published in 2020 comparing between TIP and the TIP with dorsal inlay preputial graft in which TIP performed in 350 cases and grafted TIP in 267 cases and included 2 prospective, 2 retrospective, and 2 randomized studies and did not demonstrate any significant difference regarding postoperative complications as urethrocutaneous fistula, meatal stenosis or glanular dehiscence which can be summarized in the following table ${ }^{(23)}$.
Table (4): Meta-analyses of postoperative complications when all studies were considered ${ }^{(23)}$.

\begin{tabular}{|c|c|c|c|}
\hline Primary outcome & $\begin{array}{l}\text { Number } \\
\text { of studies }\end{array}$ & Pooled analysi & Heterogeneity \\
\hline UCF & 5 & $\begin{array}{l}\text { RR: } 1.5 \\
95 \% \mathrm{Cl}: \\
0.8-2.8 \\
p \text {-value: } 0.20\end{array}$ & $\begin{array}{l}I^{2}: 0 \% \\
p \text {-value: } 0.84\end{array}$ \\
\hline $\begin{array}{l}\text { Meatal/urethral } \\
\text { stenosis }\end{array}$ & 6 & $\begin{array}{l}\text { RR: } 2.7 \\
95 \% \mathrm{Cl}: \\
0.8-9.3 \\
\text { p-value: } 0.12\end{array}$ & $\begin{array}{l}I^{2}: 59.2 \% \\
p \text {-value: } 0.03\end{array}$ \\
\hline $\begin{array}{l}\text { Wound } \\
\text { dehiscence }\end{array}$ & 4 & $\begin{array}{l}\text { RR: } 0.7 \\
95 \% \mathrm{Cl}: \\
0.3-1.8 \\
p \text {-value: } 0.48\end{array}$ & $\begin{array}{l}I^{2}: 0 \% \\
p \text {-value: } 0.78\end{array}$ \\
\hline $\begin{array}{l}\text { Total } \\
\text { complications }\end{array}$ & 6 & $\begin{array}{l}\text { RR: } 1.7 \\
95 \% \mathrm{Cl}: \\
0.9-3.3 \\
\text { p-value: } 0.10\end{array}$ & $\begin{array}{l}I^{2}: 68.6 \% \\
p \text {-value: } 0.007\end{array}$ \\
\hline
\end{tabular}

UCF, urethrocutaneous fistula; $\mathrm{RR}$, relative risk; $\mathrm{Cl}$, confidence interval.

The functional outcomes of hypospadias surgery are a cardinal goal that must be evaluated postoperatively; the principal aim of the follow-up after hypospadias repair should be early detection of the obstruction. Gonzalez's systematic review reported very high poor flow rates after ordinary TIP repair which is wide-ranged $7 \%-67 \%$. Also, another study documented obstructed uroflow in $42 \%$ of cases who underwent TIP urethroplasty (24, 25).

From the practical point of view, it is difficult to assess the obstruction of the neourethra in non-toilet trained children and also, on the other hand, the toilet trained children the objective assessment of obstruction varies widely, uroflowmetry is considered the most reliable noninvasive technique for evaluation of the functional outcome of repair, As the urinary flow reflects both urethral function and also bladder functions so if there is abnormal bladder function the uroflow may not represent the urethral function ${ }^{(26)}$.

Despite the wide variety between studies that compared between the uroflowmetry after TIP and grafted TIP, our study had compared the uroflow in the cases after 3 months and 6 months postoperatively in both groups in a toilet trained children which were 41 cases (19 in TIP group and 22 in grafted TIP group) (68.3\%) of all sample size which is considered a very high percentage compared to the previous studies, our study showed that no significant difference between both techniques in the $3^{\text {rd }}$ month while in the $6^{\text {th }}$ month there was a significant improvement of the Q max in the grafted TIP group than the TIP group. Similarly, Holmdahl et al. ${ }^{(27)}$ and El-Hout et al. ${ }^{(28)}$ noticed an 
improvement of Qmax within 8 months period and improves over time.

\section{CONCLUSION}

Our study had shown that both the classic TIP repair and grafted TIP repair were comparable in the overall success rate(p 0.718) which was in the classic TIP $(83.3 \%)$ and TIP with a preputial graft $(86.7 \%)$ and the postoperative complications while the functional outcomes which were assessed by the uroflowmetry by comparing between $3^{\text {rd }}$ month and $6^{\text {th }}$ month uroflow there was no significant difference in $\mathrm{Q}$ max between the two procedures ( $\mathrm{p}$ 0.146) while there was a significant improvement in $\mathrm{Q}$ max in the $6^{\text {th }}$ month ( $\mathrm{p}$ 0.000) so; the grafted TIP may be superior regarding the functional outcomes at the intermediate-term follow up and that needs more studies for long term follow up.

\section{REFERENCES}

1. Barbaro M, Wedell A, Nordenström A (2011): Disorders of sex development. In Seminars in Fetal and Neonatal Medicine, 16(2): 119-127).

2. Snodgrass WT (2016): Hypospadias. 11th ed. Philadelphia: Elsevier-Saunders, Pp. 212.

3. Kishk T, Elsheikh Y, Elkashty $\mathrm{S}$ et al. (2018): Comparative study between tubularized incised plate urethroplasty with and without dorsal inlay graft. Menoufia Medical Journal, 31(1):212.

4. Arshadi H, Sabetkish S, Kajbafzadeh A (2017): Modified tubularized incised plate urethroplasty reduces the risk of fistula and meatal stenosis for proximal hypospadias: a report of 63 cases. International Urology and Nephrology, 49(12):2099-104.

5. Sarma V (2020): The feasibility of urethral plate preservation in proximal and mid-penile hypospadias: sequential and anatomical approach to the repair. Annals of Pediatric Surgery, 16(1):1-9.

6. Snodgrass W (1994): Tubularized, incised plate urethroplasty for distal hypospadias. The Journal of Urology, 151(2):464-5.

7. Braga L, Henrique P, Armando J et al. (2016): Tubularized incised plate urethroplasty for distal hypospadias: a literature review." Indian journal of urology: IJU: journal of the Urological Society of India, 24(28): 219.

8. González R, Ludwikowski B (2013): Snodgraft technique for the treatment of primary distal hypospadias: pushing the envelope. Miroglu J., 188: 938-942. J Urol., 189:1170.

9. Kolon T, Gonzales E (2000): The dorsal inlay graft for hypospadias repair. J Urol., 163:1941-3.

10. Arlen AM, Kirsch AJ, Leong T et al. (2015): Further analysis of the Glans-Urethral Meatus-Shaft (GMS) hypospadias score: Correlation with postoperative complications. J Pediatr Urol., 11:71.1-71.5.

11. Van der T, de Jong T, de Gier R et al. (2013): Introducing the HOPE (Hypospadias Objective Penile Evaluation)score: a validation study of an objective scoring system for evaluating cosmetic appearance in hypospadias patients. Journal of Pediatric Urology, 9(6):1006-16.
12. Holland AJ, Smith GH, Ross FI et al. (2001): HOSE: an objective scoring system for evaluating the results of hypospadias surgery. BJU International, 88(3):255-8.

13. Snodgrass W, Koyle M, Manzoni G et al. (1996): Tubularized incised plate hypospadias repair: results of a multicenter experience. The Journal of Urology, 156(2):839-41.

14. Shimotakahara A, Nakazawa N, Wada A et al. (2011): Tubularized incised plate urethroplasty with dorsal inlay graft prevents meatal/neourethral stenosis: a single surgeon's experience. J Pediatr Surg., 46:2370-2.

15. Nerli B, Guntaka A, Patil $R$ et al. (2014): Dorsal inlay inner preputial graft for primary hypospadias repair. African Journal of Paediatric Surgery, 11(2):105.

16. Mouravas V, Filippopoulos A, Sfoungaris D (2014): Urethral plate grafting improves the results of tubularized incised plate urethroplasty in primary hypospadias. Journal of Pediatric Urology, 10 (3): 463-468.

17. Pan P (2019): Can grafted tubularized incised plate urethroplasty be used to repair narrow urethral plate hypospadias? Its functional evaluation using uroflowmetry. J Indian Assoc Pediatr Surg., 24:247.

18. Leslie B, Jesus LE, El-Hout Y et al. (2011): Comparative histological and functional controlled analysis of tubularized incised plate urethroplasty with and without dorsal inlay graft: a preliminary experimental study in rabbits. The Journal of Urology, 186(4):1631-7.

19. Holland A, Smith G (2000): Effect of the depth and width of the urethral plate on tubularized incised plate urethroplasty. J Urol., 164:489-91.

20. Nguyen MT, Snodgrass WT (2004): Effect of urethral plate characteristics on tubularized incised plate urethroplasty. J Urol., 171:1260-2.

21. Silay MS, Sirin H, Tepeler A, et al. (2012): Snodgraft technique for the treatment of primary distal hypospadias: pushing the envelope. The Journal of Urology, 188(3):93842.

22. Pfistermuller K, McArdle A, Cuckow P (2015): Metaanalysis of complication rates of the tubularized incised plate (TIP) repair. J Pediatr Urol., 11:54-9

23. Nguyen M, Snodgrass W (2004): Effect of urethral plate characteristics on tubularized incised plate urethroplasty. The Journal of Urology, 171(3):1260-2.

24. Alshafei A, Cascio S, Boland F et al. (2020): Comparing the outcomes of tubularized incised plate urethroplasty and dorsal inlay graft urethroplasty in children with hypospadias: a systematic review and meta-analysis. Journal of Pediatric Urology, 16(2):154-161.

25. González R, Ludwikowski B (2011): Importance of urinary flow studies after hypospadias repair: a systematic review. International Journal of Urology, 18(11):757-61.

26. Scarpa MG, Castagnetti M, Berrettini A et al. (2010): Urinary function after Snodgrass repair of distal hypospadias: comparison with the Mathieu repair. Pediatric Surgery International, 26(5):519-22.

27. Garibay JT, Reid C, Gonzalez R (1995): Functional evaluation of the results of hypospadias surgery with uroflowmetry. The Journal of Urology, 154(2):835-6.

Holmdahl G, Karström L, Abrahamsson K et al. (2006): Hypospadias repair with tubularized incised plate. Is uroflowmetry necessary postoperatively? Journal of Pediatric Urology, 2(4):304-7. 